\title{
Plough-extrusion Forming for Making Micro-groove Heat Pipes on Hydrostatic Thrust Bearings of Heavy Machinery
}

\author{
Xibing $\mathrm{Li}^{1}$ - Zhe $\mathrm{Yu}^{1}$ - Xizhao Li ${ }^{2}$ - Weixiang $\mathrm{Li}^{1}$ - Tengyue Zou ${ }^{1}$,* \\ ${ }^{1}$ Fujian Agriculture and Forestry University, College of Mechanical and Electrical Engineering, China \\ ${ }^{2}$ Shandong Labor Vocational and Technical College, Department of Intelligent Manufacturing, China
}

The present paper focuses on the manufacturing of micro-groove heat pipes on hydrostatic thrust bearings of heavy machinery. Special multitooth tools were designed for plough-extrusion forming heat pipes on flat copper. Experimental results were conducted to determine whether the plough-extrusion forming could achieve better performance than traditional wire electrical discharge. Furthermore, the processing using multi-tooth tool with $10 \mathrm{~mm}$ length, 55 tooth number, $0.25 \mathrm{~mm}$ tooth depth and 0.22 tooth top width was found to achieve the best performance among the six optional tools. The $50 \mathrm{~mm} / \mathrm{min}$ forming speed was determined to acquire the best surface quality of the microgroove structure. Through heat transfer testing, the theoretical model for a micro-groove heat pipe made by plough-extrusion forming was also verified.

Keywords: heat pipe, heat dissipation, micro-groove, heavy machine

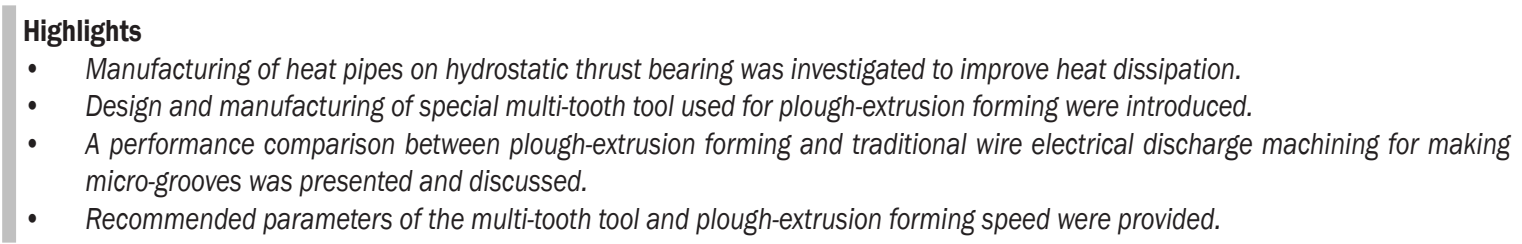

\section{INTRODUCTION}

Due to the increase in the accuracy requirements of large parts in industrial environments, improving the machining efficiency and accuracy of heavy computer numerical control $(\mathrm{CNC})$ vertical lathes is becoming an important issue. The hydrostatic thrust bearing is a critical component in heavy $\mathrm{CNC}$ vertical lathes, and its performance directly affects the machining quality and efficiency of the entire device. During machining, the temperature of the oil film on the hydrostatic thrust bearing will rise rapidly with the increase of the rotating speed, which may make the loadbearing oil film thinner and prone to rupture, leading to lubrication failure [1]. Therefore, to control the temperature of oil film for hydrostatic thrust bearing is a problem that must be solved for high-speed machining. A heat pipe is a very effective device for transmitting heat with the advantages of high thermal conductivity, good isothermal characteristics, fast thermal response, simple construction and easy control with no external electric drive [2] and [3]. It can be used under various application circumstances. A new design is presented to integrate heat-pipes into a nuclear cooling system [4]. Light-emitting-diode cooling [5] and battery-pack cooling [6] also need help from heat pipes to remain stable. Micro-grooved aluminium flat plate heat pipes are adopted to improve the thermal efficiency of solar collectors [7]. The data centres for the Internet or cloud computing also require them for their air conditioning systems [8]. There are also many studies on promoting the efficiency of heat pipes. Flat-plate micro heat pipes with different geometries were designed and fabricated to determine the best geometries of wicking structures to improve efficiency [9]. Micro-pillars added inside the microgrooves have been proven not only to improve the wettability of micro-grooves but also increase the heat transfer capability of two-phase flow inside the micro heat pipe [10]. Nanofluids are shown to be effective means for enhancing heat transfer of heat pipes [11]. A new ultra-thin aluminium flat heat pipe is studied with regards to advantages including light weight, good heat transfer characteristics, being convenient to manufacture, and low cost [12]. It can meet the heat dissipation requirements of electronic equipment but does not meet the function of high load-bearing heat dissipation. The research shows that the rotational speed, oil viscosity, bearing groove size and position have a great influence on the temperature performance of hydrostatic thrust bearing [13]. It has also been discovered that the heat pipes set on oil pad and hydrostatic thrust bearing can take away the most heat generated by the shear of the oil film and effectively control the temperature rise and thermal deformation 
to avoid dry friction and improve the machining quality of equipment [14].

The heat transfer performance of the heat pipe is closely related to the structure of the capillary wick in it. According to different structures and manufacturing methods for the capillary wick, the heat pipes can be divided into micro-sintered heat pipes and microgroove heat pipes. The micro-sintered heat pipe has a high heat transfer capacity, but the manufacturing process is complicated. Moreover, the structure of sintered capillary wick is easily damaged, and the copper powder particles in the wick structure are prone to fall off when subjected to heavy load deformation [15]. However, the capillary wick structure of microgroove heat pipe is directly formed on the inner wall of the pipe [16]. It is lightweight, with no contact thermal resistance, fast thermal response and is not easy to be damaged. In order to improve the capillary performance of the two-phase heat transfer device, an aluminium micro-groove core with a cavity array is developed using the orthogonal plough-extrusion method [17]. It is also found that the wick structure with liquid tanks can improve the performance of loop heat pipes [18]. Studies show that the maximum heat transfer capacity can be achieved through rectangular or triangular grooves [19]. Moreover, the converging micro-channel heat pipe has been developed to obtain better capillary performance than the straight microchannel heat pipe [20].

Studies on the designing and manufacturing of the micro-groove heat pipe found that the heat pipe can perform better with scratches and cracks generated synergistically. Under the same conditions, the thermal conductivity of rough micro-groove heat pipe is more than 2 times higher than that of the smooth microgroove heat pipe. Therefore, a special multi-tooth tool is designed in this paper to form rough micro-grooves on the inner wall of the flat using the plough-extrusion forming mechanism. It can be well applied to solve the problem of thermal control for hydrostatic thrust bearing.

As shown in Fig. 1, the inside pipe is drawn to be under a negative pressure of $1.3 \times\left(10^{-1}\right.$ to $\left.10^{-4}\right) \mathrm{Pa}$ and then charged with working fluid. One end of the tube is the evaporation section, and the other end is the condensation section. The insulating section can be arranged in the middle as needed. When the evaporation section is heated, the working liquid in the capillary wick evaporates and vaporizes. The steam flows to the condensation section under a slight pressure difference to release heat to form a liquid. The liquid then flows back to the evaporation section by the capillary suction generated by the micro-groove.
Thus, the heat is transferred from one end of the heat pipe to the other end. Therefore, the heat transfer limit of the capillary wick structure determines the heat transfer capacity of the micro-groove heat pipe.

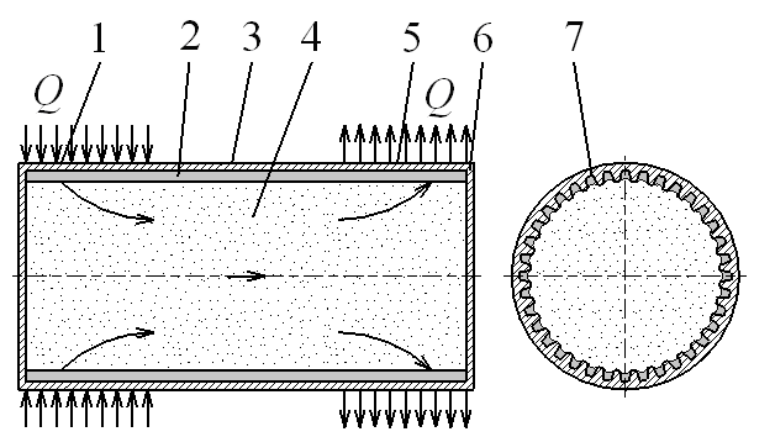

Fig. 1. The working mechanism of micro-groove heat pipe; 1. evaporation section, 2. working fluid area, 3. insulation section, 4. steam area, 5. condensation section, 6. pipe shell area, 7. trapezoidal groove core

\section{THE WORKING PRINCIPLE OF MICRO-GROOVE HEAT PIPE}

In the process of heat transfer, the heat pipe includes the following six interrelated main processes: 1) Heat is transferred from the heat source to the liquid-vapour interface through the heat pipe wall and the wick filled with working liquid; 2) The liquid evaporates on the liquid-vapour interface in the evaporation section; 3) The steam flows from the evaporation section to the condensation section; 4) Steam condenses on the vapour-liquid interface in the condensation section; 5) Heat is transferred from the vapour-liquid interface to the cold source through the wick, liquid and tube wall; 6) The condensed working liquid flows back to the evaporation section due to capillary action in the wick.

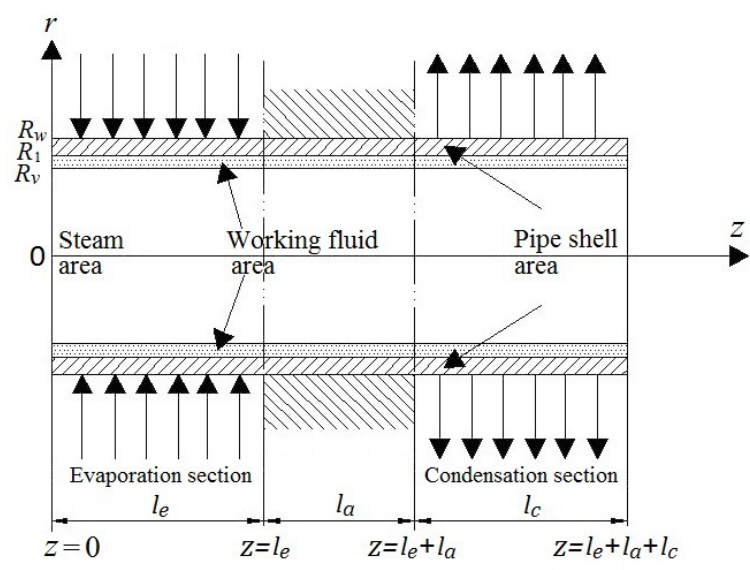

Fig. 2. Model and coordinate of micro-groove heat pipe 
As shown in Fig. 2, a heat pipe can be divided into three areas from the inside to the outside: the steam area, the working fluid area, and the pipe shell area. In the steam area of the heat pipe, the steam flow can be described with the Navier-Stokes equation. For a stable incompressible axisymmetric laminar flow, the heat transfer equation is shown in Eq. (1).

$$
\rho_{s} C_{P s}\left(v_{s} \frac{\partial T_{s}}{\partial r}+u_{s} \frac{\partial T_{s}}{\partial z}\right)=k_{s}\left[\frac{1}{r} \frac{\partial\left(r \frac{\partial T_{s}}{\partial r}\right)}{\partial r}+\frac{\partial^{2} T_{s}}{\partial z^{2}}\right],
$$

where $\rho_{s}$ represents the steam density, $v_{s}$ is the radial velocity, $u_{S}$ denotes the axial velocity, $C_{P_{S}}$ is the steam specific heat capacity, $T_{S}$ denotes the steam temperature, and $k_{s}$ represents the steam thermal conductivity. For the working fluid area, the heat transfer equation can be described as shown in Eq. (2).

$$
\rho_{l} C_{P l}\left(v_{l} \frac{\partial T_{l}}{\partial r}+u_{l} \frac{\partial T_{l}}{\partial z}\right)=k_{e f f}\left[\frac{1}{r} \frac{\partial\left(r \frac{\partial T_{l}}{\partial r}\right)}{\partial r}+\frac{\partial^{2} T_{l}}{\partial z^{2}}\right]
$$

where $\rho_{l}$ represents the liquid density, $v_{l}$ is the radial velocity, $u_{l}$ is the axial velocity, $C_{P l}$ denotes the liquid specific heat capacity, $k_{\text {eff }}$ represents the liquid effective thermal conductivity, and $T_{l}$ denotes the liquid temperature. Furthermore, the heat transfer principle follows Eq. (3) in the pipe shell area.

$$
\begin{aligned}
& \frac{1}{r} \frac{\partial}{\partial r}\left(k_{w} r \frac{\partial T_{l}}{\partial r}\right)+\frac{\partial}{\partial z}\left(k_{w} \frac{\partial T_{w}}{\partial z}\right)= \\
& =m k_{w}\left(T_{w}-T_{s}\right) \frac{\operatorname{sh}(2 m w)}{\operatorname{th}(2 m w)},
\end{aligned}
$$

where $m=\sqrt{64 k_{\text {eff }} /\left(k_{w} w\right)}, w$ represents the channel width, $k_{w}$ is the solid thermal conductivity, and $T_{w}$ denotes the solid wall temperature. The more detailed description for the principle of micro-groove heat pipes can be found in previous research studies [21] and [22].

Although the heat transfer capacity of the heat pipe is great, it is impossible to increase the heat load indefinitely, because many factors restrict the heat transfer capacity of the heat pipe, including viscosity limit, sonic limit, carrying limit, boiling limit and capillary limit, etc. The viscosity limit refers to the maximum heat transfer when the pressure of the steam drops to zero at the end of the condensation section of the micro heat pipe due to the effect of the viscous force. This limit will be encountered when the working temperature of the micro heat pipe is lower than the normal working temperature range. Therefore, it is also called the steam pressure limit [23]. The viscosity limit of the micro-groove heat pipe follows Eq. (4).

$$
Q_{v i, \max }=\frac{\pi d_{v}^{4} h_{f g} \rho_{v} p_{v}}{128 \mu_{v}\left(l_{e}+2 l_{a}+l_{c}\right)},
$$

where $d_{v}$ represents the diameter of the steam chamber of the micro heat pipe $[\mathrm{m}], h_{f g}$ denotes the latent heat of vapourization of the working fluid $[\mathrm{J} / \mathrm{kg}], \rho_{v}$ is the vapour density of the working fluid $\left[\mathrm{kg} / \mathrm{m}^{3}\right], p_{v}$ presents the saturated vapor pressure of the working fluid [Pa], $\mu_{v}$ denotes the vapour viscosity of the working fluid $\left[\mathrm{N} \cdot \mathrm{s} / \mathrm{m}^{2}\right], l_{e}$ is the length of the evaporation section $[\mathrm{m}], l_{c}$ is the length of the condensation section [m], $l_{a}$ denotes the length of the adiabatic section [m]. The sonic limit refers to maximum heat transfer limit when the steam flows in the micro heat pipe and may reach the speed of sound or supersonic speed at the exit of the evaporation section to occur blocking because of the effect of inertial force [24]. The sonic limit of the micro-groove heat pipe follows Eq. (5).

$$
Q_{s, \max }=\frac{\pi d_{v}^{2}}{4} \rho_{v} h_{f g} \sqrt{\frac{\gamma_{v} R_{0} T_{v}}{2\left(\gamma_{v}+1\right) M}},
$$

In addition to the parameters mentioned before, where $\gamma_{v}$ represents the steam specific heat ratio $(5 / 3$ for monoatomic steam, $7 / 5$ for diatomic steam, $4 / 3$ for polyatomic steam), $R_{0}$ is the general gas constant $[\mathrm{J} /$ $(\mathrm{kmol} \cdot \mathrm{K})], T_{v}$ denotes the working temperature of the micro heat pipe [K], $M$ is the relative molecular weight of the working fluid [ $\mathrm{g} / \mathrm{mol}]$. The carrying limit refers to the maximum heat transfer that the shear force at the liquid-vapour interface may tear the liquid on the surface of the wick and bring it into the vapour flow when the steam velocity in the micro heat pipe is high enough. The carrying limit of the micro-groove heat pipe follows Eq. (6).

$$
Q_{e, \max }=\frac{\pi d_{v}^{2}}{4} h_{f g} \sqrt{\frac{\rho_{v} \sigma}{2 W}} .
$$

In addition to the parameters mentioned before, where $\sigma$ represents the surface tension of the working fluid $[\mathrm{N} / \mathrm{m}]$ and $W$ denotes the width of the microgroove $[\mathrm{m}]$, when the micro heat pipe is at a low heat flow rate, part of the heat is transferred to the vapour-liquid interface through the wick and liquid, and the other part reaches the vapour-liquid interface through natural convection and forms the evaporation of the liquid. If the heat flow increases, the liquid in contact with the tube wall will gradually overheat and generate vapour bubbles in the nucleation centre. The formation of vapour bubbles should be avoided when the micro heat pipe is working, because once vapour 
bubbles are formed in the wick, if it cannot smoothly pass through the wick and move to the surface of the liquid; it may hinder the circulation of the working fluid and cause the surface to overheat. Therefore, the maximum heat transfer amount of the evaporation section when the liquid generates bubbles at the tube wall is called the boiling limit [25]. The boiling limit of the micro-groove heat pipe follows Eq. (7).

$$
\begin{aligned}
Q_{b, \max }= & \frac{2 \pi l_{e} k_{e} T_{v}}{h_{f g} \rho_{v} \ln \left(1+\frac{2 \delta}{d_{v}}\right)} \\
& \times\left(\frac{2 \sigma}{r_{b}}-\frac{4 \sigma \delta}{W \sqrt{\left(W-W_{b}\right)^{2}+4 \delta^{2}}}\right) .
\end{aligned}
$$

Besides the parameters mentioned before, where $k_{e}$ represents the effective thermal conductivity of the liquid-filled wick $[\mathrm{W} /(\mathrm{m} \cdot \mathrm{K})], \delta$ denotes the depth of the micro-groove $[\mathrm{m}], r_{b}$ is the critical radius of bubble generation $[\mathrm{m}]$, and $W_{b}$ denotes the width of the bottom side of the micro-groove [m]. The capillary limit of the micro-groove heat pipe is the maximum heat transferred by the capillary suction force generated by the micro-groove capillary wick and the working fluid. In most cases, the mathematical model of the capillary heat transfer limit of the microgroove heat pipe can be derived from Chi [26] under the assumption that the heat load is evenly distributed in the evaporation and condensation sections, and is derived from the vapour flow under laminar incompressible conditions as Eq. (8) shows.

$$
Q_{c a, \max }=\frac{2 \sigma / r_{c}-\rho_{l} g d_{v} \cos \varphi \pm \rho_{l} g l \sin \varphi}{\left(F_{l}+F_{v}\right) l_{e f f}},
$$

where the parameters are defined as below:

1) $r_{c}$, the $2 / r_{c}$ is the maximum possible value of the wick structure $\left(1 / R_{1}+1 / R_{2}\right)$. As the trapezoidal micro-groove wick structure shown in Fig. 3,

$R_{1}=W \sqrt{\left(W-W_{b}\right)^{2}+4 \delta^{2}} / 4 \delta, \quad R_{2}=\infty$.

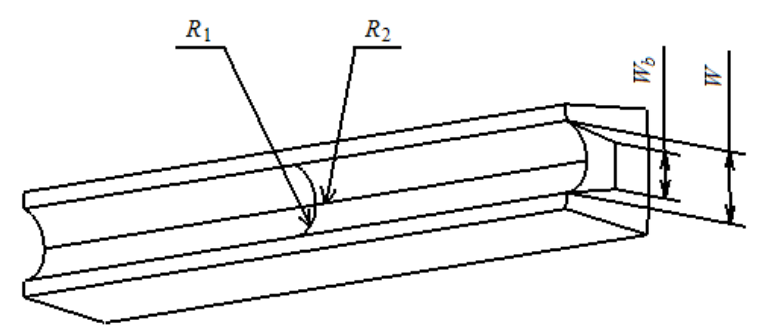

Fig. 3. Effective capillary radius calculation of trapezoidal micro-groove wick
Thus, $\frac{2}{r_{c}}=\frac{1}{R_{1}}+\frac{1}{R_{2}}=\frac{4 \delta}{W \sqrt{\left(W-W_{b}\right)^{2}+4 \delta^{2}}}+\frac{1}{\infty}$

$$
=\frac{4 \delta}{W \sqrt{\left(W-W_{b}\right)^{2}+4 \delta^{2}}} \text { and }
$$

and $r_{c}=W \sqrt{\left(W-W_{b}\right)^{2}+4 \delta^{2}} / 2 \delta$.

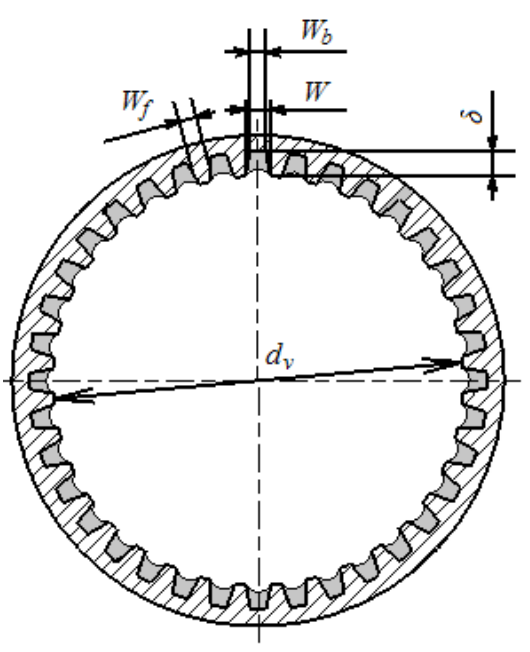

Fig. 4. Trapezoidal micro-groove wicking cross-section

2) $g=9.81 \mathrm{~N} / \mathrm{kg}$.

3) $F_{l}$ is obtained by considering the various types of wicks and the loss of liquid flow pressure in different forms of flow channels [27], which are calculated by Eq. (9).

$$
F_{l}=\frac{\mu_{l}}{K A_{W} \rho_{l} h_{f g}},
$$

where $K$ denotes the permeability of trapezoidal grooved wick calculated by Eq. (10) in which $\varepsilon$ represents the void ratio of trapezoidal grooved wick calculated by Eq. (11) and $r_{h l}$ is hydraulic radius defined by Eq. (12) and calculated by Eq. (13) for trapezoidal grooved wick as shown in Fig. 4; The $f_{l} R e_{l}$ in Eq. (10) can be found in Fig. 5 where $\alpha=W / 2 \delta$ if $W \leq 2 \delta$ and $\alpha=2 \delta / W$ if $W>2 \delta ; A_{W}$ represents the cross-sectional area of wick structure calculated by Eq. (14). Thus, the $F_{l}$ can be calculated by Eq. (15).

$$
\begin{gathered}
K=\frac{2 \varepsilon \cdot r_{h l}^{2}}{f_{l} R e_{l}}, \\
\varepsilon=\frac{n\left(W+W_{b}\right) \delta}{2\left(\pi\left(\frac{d_{v}}{2}+\delta\right)^{2}-\pi\left(\frac{d_{v}}{2}\right)^{2}\right)}=\frac{n\left(W+W_{b}\right)}{2 \pi\left(d_{v}+\delta\right)},
\end{gathered}
$$




$$
\begin{gathered}
r_{h l}=2 A_{l} / C_{l}, \\
r_{h l}=\frac{\left(W+W_{b}\right) \delta}{W_{b}+\sqrt{\left(W-W_{b}\right)^{2}+4 \delta^{2}}}, \\
A_{W}=\pi\left(\frac{d_{v}}{2}+\delta\right)^{2}-\pi\left(\frac{d_{v}}{2}\right)^{2}=\pi\left(d_{v}+\delta\right) \delta, \\
F_{l}=\frac{\left(W_{b}+\sqrt{\left(W-W_{b}\right)^{2}+4 \delta^{2}}\right)^{2} f_{l} R e_{l} \mu_{l}}{n\left(W+W_{b}\right)^{3} \delta^{3} \rho_{l} h_{f g}} .
\end{gathered}
$$

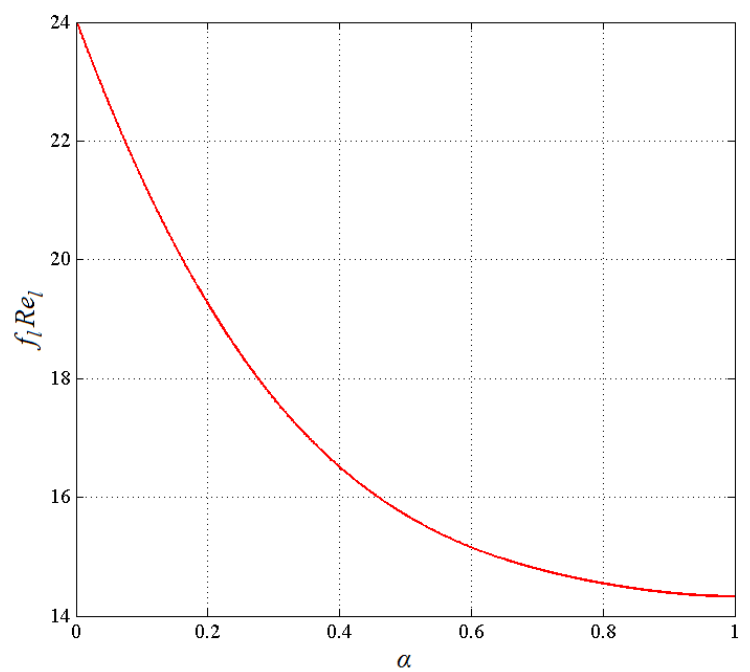

Fig. 5. Drag coefficient of laminar flow in trapezoidal micro-groove [28]

4) $F_{v}$ is the friction coefficient of the steam flow according to the flow conditions of the steam, which is related to the steam Reynolds number and the Mach number. The steam Reynolds number $R e_{v}$ can be calculated with Eq. (16).

$$
R e_{v}=\frac{2 r_{h v} Q}{A_{v} \mu_{v} h_{f g}},
$$

where, $r_{h v}=d_{v} / 2$ for micro heat pipe with a circular steam chamber, then Eq. (16) can be expressed as Eq. (17).

$$
R e_{v}=\frac{4 Q}{\pi d_{v} \mu_{v} h_{f g}} .
$$

The Mach number $M_{v}$ can be calculated by Eq.

$$
M_{v}=\frac{Q}{A_{v} \rho_{v} h_{f g} \sqrt{\gamma_{v} R_{v} T_{v}}}=\frac{4 Q}{\pi d_{v}^{2} \rho_{v} h_{f g} \sqrt{\gamma_{v} R_{0} T_{v} / M}} .
$$

Then the parameter $F v$ can be calculated by Eqs. (19) to (22) according to different situations.

a. If $R e_{v} \leq 2300$ and $M_{v} \leq 0.2$

$$
F_{v}=\frac{8 \mu_{v}}{A_{v} r_{h v}^{2} \rho_{v} h_{f g}}=\frac{128 \mu_{v}}{\pi d_{v}^{4} \rho_{v} h_{f g}} .
$$

b. If $R e_{v} \leq 2300$ and $M_{v}>0.2$

$$
\begin{aligned}
F_{v} & =\frac{8 \mu_{v}}{A_{v} r_{h v}^{2} \rho_{v} h_{f g}}\left(1+\frac{\gamma_{v}-1}{2} M_{v}^{2}\right)^{-1 / 2} \\
& =\frac{128 \mu_{v}}{\pi d_{v}^{4} \rho_{v} h_{f g}}\left(1+\frac{\gamma_{v}-1}{2} M_{v}^{2}\right)^{-1 / 2} .
\end{aligned}
$$

c. If $\operatorname{Re}_{v}>2300$ and $M_{v} \leq 0.2$

$$
\begin{aligned}
F_{v} & =\frac{0.038 \mu_{v}}{A_{v} r_{h v}^{2} \rho_{v} h_{f g}}\left(\frac{2 r_{h v} Q}{A_{v} h_{f g} \mu_{v}}\right)^{3 / 4} \\
& =\frac{0.608 \mu_{v}}{\pi d_{v}^{4} \rho_{v} h_{f g}}\left(\frac{4 Q}{\pi d_{v} h_{f g} \mu_{v}}\right)^{3 / 4} .
\end{aligned}
$$

d. If $R e_{v}>2300$ and $M_{v}>0.2$

$$
\begin{aligned}
F_{v} & =\frac{0.038 \mu_{v}}{A_{v} r_{h v}^{2} \rho_{v} h_{f g}}\left(\frac{2 r_{h v} Q}{A_{v} h_{f g} \mu_{v}}\right)^{3 / 4}\left(1+\frac{\gamma_{v}-1}{2} M_{v}^{2}\right)^{-3 / 4} \\
& =\frac{0.608 \mu_{v}}{\pi d_{v}^{4} \rho_{v} h_{f g}}\left(\frac{4 Q}{\pi d_{v} h_{f g} \mu_{v}}\right)^{3 / 4}\left(1+\frac{\gamma_{v}-1}{2} M_{v}^{2}\right)^{-3 / 4} .
\end{aligned}
$$

Thus, the capillary heat transfer limit of the trapezoidal micro-groove heat pipe can be calculated by Eq. (23).

$Q_{c a, \max }=\frac{\frac{W \sigma \delta}{W \sqrt{\left(W-W_{b}\right)^{2}+4 \delta^{2}}}-\rho_{l} g d_{v} \cos \varphi \pm \rho_{l} g l \sin \varphi}{\left(\frac{\left(W_{b}+\sqrt{\left(W-W_{b}\right)^{2}+4 \delta^{2}}\right)^{2} f_{l} R e_{l} \mu_{l}}{n\left(W+W_{b}\right)^{3} \delta^{3} \rho_{l} h_{f g}}+F_{v}\right) l_{e f f}}$.

Thus, when the temperature of working fluid and the effective length of the micro heat pipe are constant, the capillary limit is influenced by the diameter of the steam chamber, the top and bottom width of the trapezoidal micro-groove, the depth and number of the grooves and the flow conditions of the steam. (18). 


\section{PLOUGH-EXTRUSION FORMING USING MULTI-TOOTH TOOL}

Plough-extrusion forming of metal uses the special plough-extrusion multi-tooth tool on the machine tool to plastically deform a part of the metal on a metal wall and build fins with many micro-grooves. Thus, plough-extrusion forming is a metal-processing technology with the characteristics of both plough and extrusion. Although it uses the lathe machining, and its tool is similar to the turning tool, the forming mechanism is different from turning. Ploughextrusion forming has both characteristics of plough and extrusion deformation. Therefore, it can be called plough-extrusion forming. Turning makes the required shape by cutting the extra metal from the material. However, plough-extrusion forming produces plastic deformation and slicing via the effect of extruding to form grooves and fins without cutting. Thus, the fin it produces is much deeper than what the turning tool does.

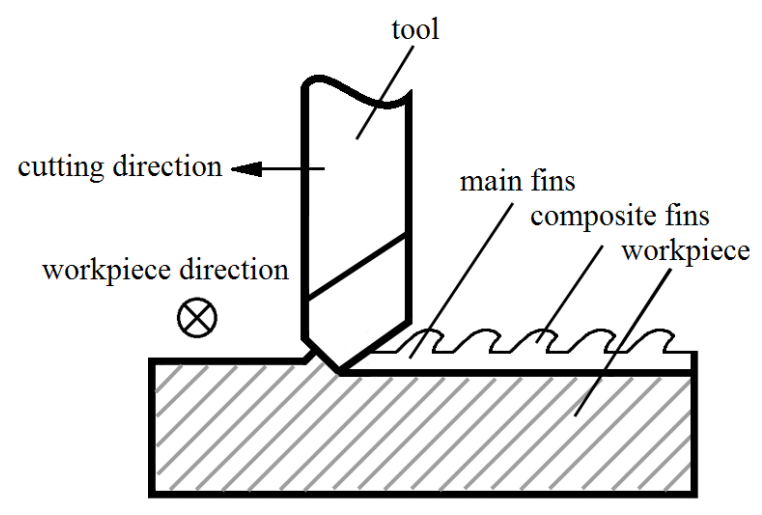

Fig. 6. The diagram of plough-extrusion forming for making fin structure

The workpiece material in this research is copper $\mathrm{T} 2$, and the tool material is bearing steel $\mathrm{GCr} 15$ or high-speed steel W18Cr4V. The workpiece is mounted on the machine tool table, as shown in Fig. 6. As mentioned before, the process of plough-extrusion forming is different from turning on common machine tools. The turning process forms the required shape by cutting the extra metal, and the removed metal materials often become chips. However, in ploughextrusion forming, a special multi-tooth tool is used to plough, crush, and tear to form sub-structures and micro-structures of fins, which are superimposed on the macro-structure. There are no chips or only a few cutting materials during machining.

For making sub-structures and micro-structures of fins, the entire plough-extrusion forming process can be divided into four stages: cut-in, extrusion, fin forming, finishing. The cut-in process uses the multitooth tool to cut the copper surface with the front blade and forms the opening of groove, then the surface metal is ploughed by pressure in front of the multitooth tool, and forcing the metal to start diverting to both sides. In the extrusion step, after the surface layer of copper is cut in, the two extrusion surfaces of the multi-tooth tool begin to extrude the metal. With the continuous deepening of the multi-tooth tool, when the applied stress of the multi-tooth tool reaches the yield limit of the copper material, the copper begins to undergo plastic deformation. The copper is then forced to flow in the direction of minimum resistance after hindered by metal resistance. In other words, the copper flows outward along the normal direction of the tool pressing surface, and the metal bulging occurs continuously on both sides of the pressing surface to form the first fin. The fin-forming process is relatively complicated, and under the combined forces of friction and extrusion, the first formed fins begin to crack to form a jagged structure. In the case in which the multi-tooth tool continues to plough and extrude, the top of each fin is re-cracked to form a periodic serrated fin structure. In the finishing step, after ploughing and extruding to form a relatively complete fin structure, the secondary extrusion surface of the multi-tooth tool will still extrude and repair on the fins formed in the previous step. At this time, a small amount of metal will undergo minor plastic deformation, and flow along the secondary extrusion surface of the multi-tooth tool to make the fin structure grow upward and form the sub-structure and micro-structure superimposed on the macrostructure. Through repeated cycles of these above four processes, the sub-structures and micro-structures of fin are continuously produced and stacked.

\section{DESIGN AND MANUFACTURE OF MULTI-TOOTH TOOL}

\subsection{Material Selection for Multi-tooth Tool}

High-speed steel is especially suitable for the manufacture of complicated tool with high thermal stability, high strength, a certain degree of hardness and wear resistance. It is easy to be shaped into a sharp cutting edge. The ploughing tool is more complex, so bearing steel material GCr15 or high-speed steel material $\mathrm{W} 18 \mathrm{Cr} 4 \mathrm{~V}$ are used. The bar diameter is chosen to be $20 \mathrm{~mm}$. 


\subsection{Design of Multi-tooth Tool}

The parameters of six designed multi-tooth tools are shown in Table 1 (the parameters in parentheses are derived from the geometric calculation, not from direct design). The cross-section of a single tooth of the multi-tooth tools is an isosceles trapezoid, and the angle between the two sides of a single tooth is $120^{\circ}$. The tool length is $10 \mathrm{~mm}$, the tooth number is 50,55 or 60 , and the depth of groove is $0.2 \mathrm{~mm}$ or $0.25 \mathrm{~mm}$. As the number and depth of tooth increase, the ploughextrusion force is also increased, and the micro-chips will become more numerous, which accelerates the wear of the tool.

\subsection{Manufacture of Multi-tooth Tool}

The manufacturing process of the multi-tooth tool is as follows:

1) The raw material is cut into bars of $10 \mathrm{~mm}$ length.

2) A centre hole of $\Phi 5 \mathrm{~mm}$ is drilled on a $\Phi 20 \mathrm{~mm}$ bar for tool mounting.
3) Heat treatment and quenching steps are shown in Figs. $7 \mathrm{a}$ and $\mathrm{b}$. There are two common kinds of materials for making multi-tooth tool for different needs, W18Cr4V6 and GCr15. For high-speed steel W18Cr4V6, it is first quenched (oil cooling) between $1200{ }^{\circ} \mathrm{C}$ and $1300{ }^{\circ} \mathrm{C}$, and then tempered 3 times at $550{ }^{\circ} \mathrm{C}$ for 1 hour each time; For bearing steel GCr15, it is first quenched between $800{ }^{\circ} \mathrm{C}$ and $860{ }^{\circ} \mathrm{C}$ (oil cold), and then tempered 1 time between $150{ }^{\circ} \mathrm{C}$ and $170{ }^{\circ} \mathrm{C}$ for 2 to 3 hours.

4) The process of wire electrical discharge machining for a multi-tooth tool is shown in Figs. $7 \mathrm{c}, \mathrm{d}$ and $\mathrm{e}$. In order to improve the efficiency of wire electrical discharge machining, the five treated bars are put on the positioner together to perform cutting, and the use of positioner can help to locate the central axis of the inner hole during the wire electrical discharge machining. A low-speed is taken to minimize the error because the wire may break if the speed is fast. If the wire breaks, the micro-grooves of the
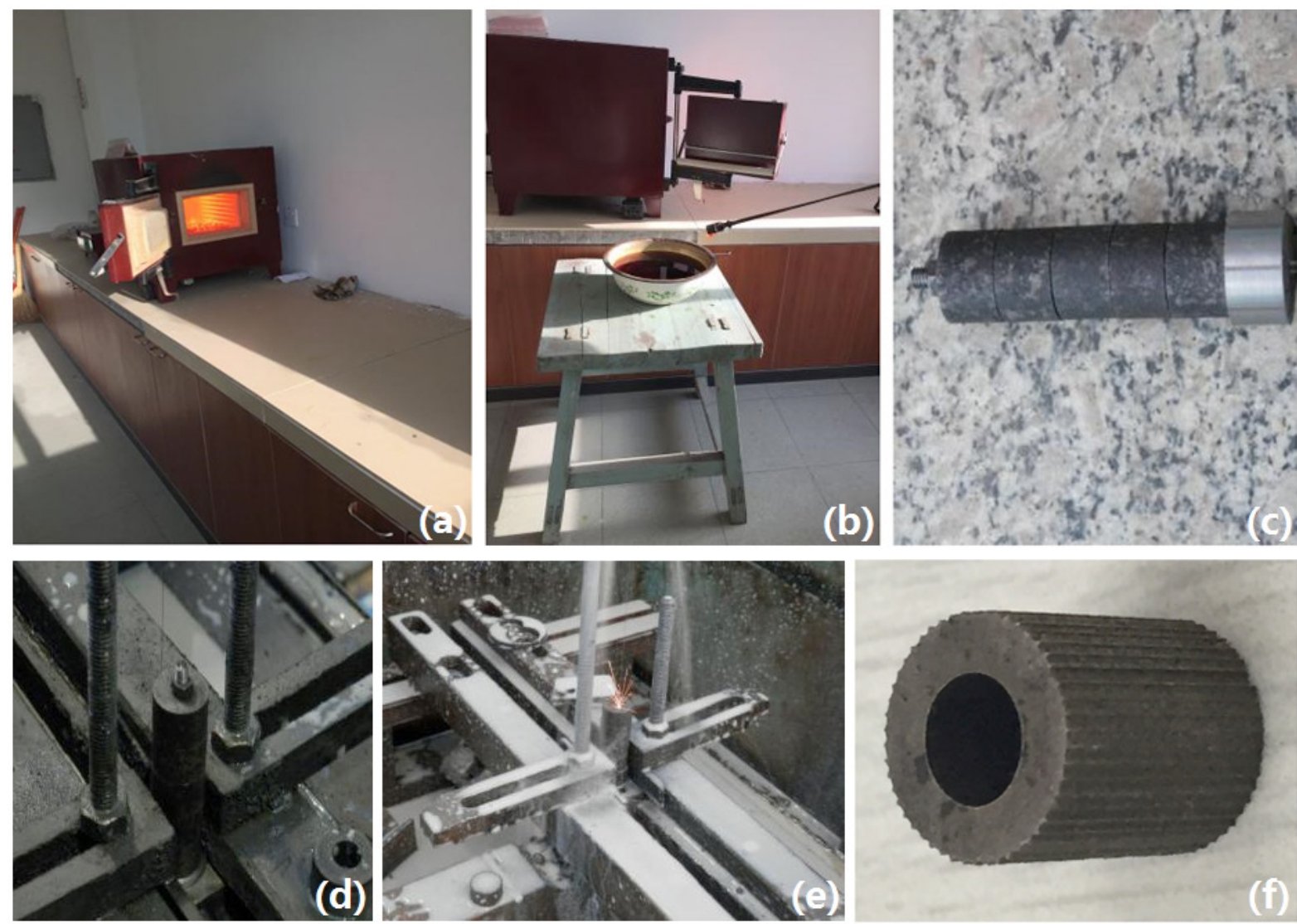

Fig. 7. Heat treatment and wire electrical discharge machining in multi-tooth tool producing; a) heating, b) quenching, c) clamping, d) workpiece localization, e) wire electrical discharge machining, f) formed multi-tooth tool 
tool cannot be machined correctly due to the positioning problem. In other words, it is not able to correspond with the point and form the correct number of micro-grooves and that will also waste the raw material of the tool. Therefore, the voltage and current of wire electrical discharge machining should be controlled within a reasonable range. In addition, the cutting wire should be as close as possible to the tool, but do not approach the material; otherwise, it will cause greater error.

5) Grinding. One end of the multi-tooth tool is sharpened, and reasonable parameters are obtained, such as the anterior horn, the dorsal horn, the rake face and the rear face.

6) Cleaning. After cleaning, the final formed multitooth tool is acquired as shown in Fig. $7 \mathrm{f}$.

\section{EXPERIMENTS OF PLOUGH-EXTRUSION FORMING AND THE RESULTS}

The plough-extrusion forming experiment was performed on the XK5032 CNC vertical lifting table milling machine. The whole procedure was as follows: 1) A plate was clamped on the worktable as shown in Fig. 8a. 2) A 3-mm-deep hole was drilled using the centre drill to effectively reduce the error from shaking when the drill meets copper block as shown in Fig. 8b. 3) The hole was drilled and reamed to an aperture of $\Phi 10 \mathrm{~mm}$ as shown in Fig. 8c; 4) The multitooth tool was mounted on the pull rod to perform plough-extrusion forming as shown in Fig. 8d. The position of the horizontal plane of the multi-tooth tool was fine-tuned, and the chamfer of the multi-tooth tool was used to guide the positioning. Then, let the pull rod directly go down without rotating for ploughextrusion forming, and the illustration of the process was shown in Fig. 8e. Finally, the formed inner microgrooves on the plate were shown in Fig. 8f.

Fig. 9 shows the comparison between wire electrical discharge machining and plough-extrusion forming for making the structure of the heat pipe. Figs. $9 \mathrm{~b}$ and e were acquired by the digital camera equipment and it was found that the wire electrical discharge machining method did not make the weight and volume of the micro-groove larger when compared with the plough-extrusion forming method, and the surface of groove was smooth without the fin structure shown in Fig. 9f. However, the surface of microgroove made by plough-extrusion forming was rough as shown in Figs. 9d and e. The surface roughness of the groove can increase the area of the surface, thereby increasing the wettability of the working fluid and improving the heat transfer performance of the flat heat pipe. Fig. 9e shows the enlarged view of micro-grooves manufactured by plough-extrusion forming, where the formed grooves have better height,
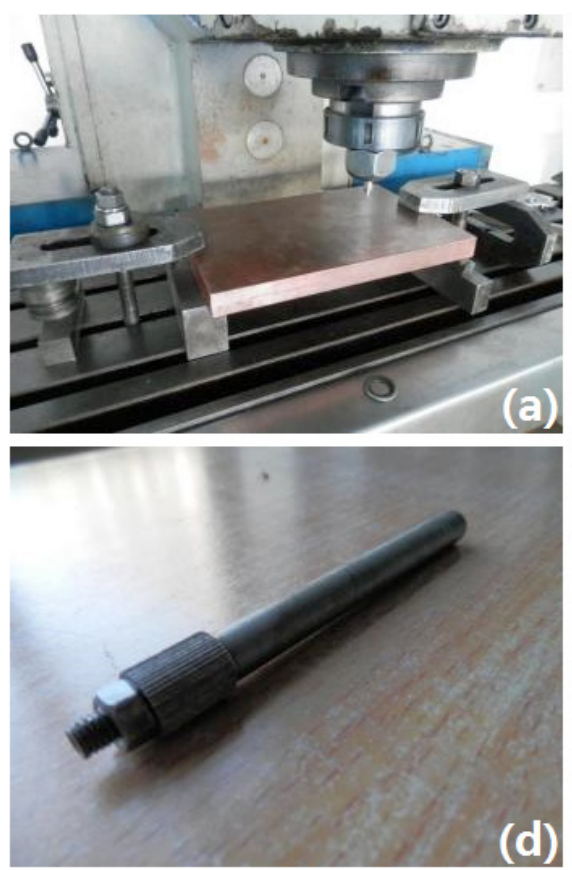
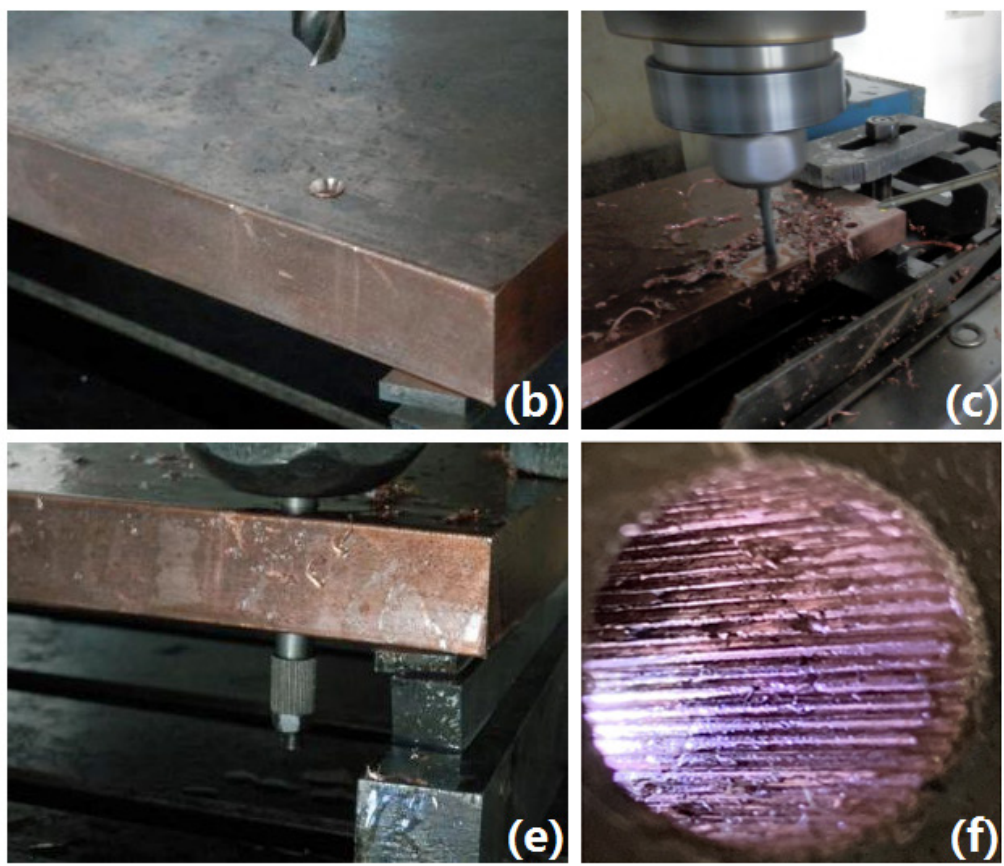

Fig. 8. Plough-extrusion forming for micro-grooves by multi-tooth tool; illustration of; a) clamping, b) central positioning, c) of drilling, d) clamping multi-tooth tool, e) plough-extrusion forming, f) formed inner micro-grooves 
depth, and width than the ones made by wire electrical discharge machining. The plough-extrusion forming also made a secondary groove structure superimposed on the main groove structure, as shown in Fig. 9c to improve the roughness.

Furthermore, the wire electrical discharge machining method is more complicated and costs more than the plough-extrusion forming method. The plough-extrusion forming can even be carried out on a simple self-made cutting platform. Thus, the plough- extrusion forming method has an advantage of making micro-grooves providing higher capillary force at a lower manufacturing cost.

For the experiment, six multi-tooth tools with different designed geometric sizes (Table 1) were adopted to compare their forming performance in plough-extrusion procedure. All these tools were made of bearing steel GCr15.The intercepted formed micro-groove of the heat pipe was magnified and focused with a 12-million-pixel digital camera device,
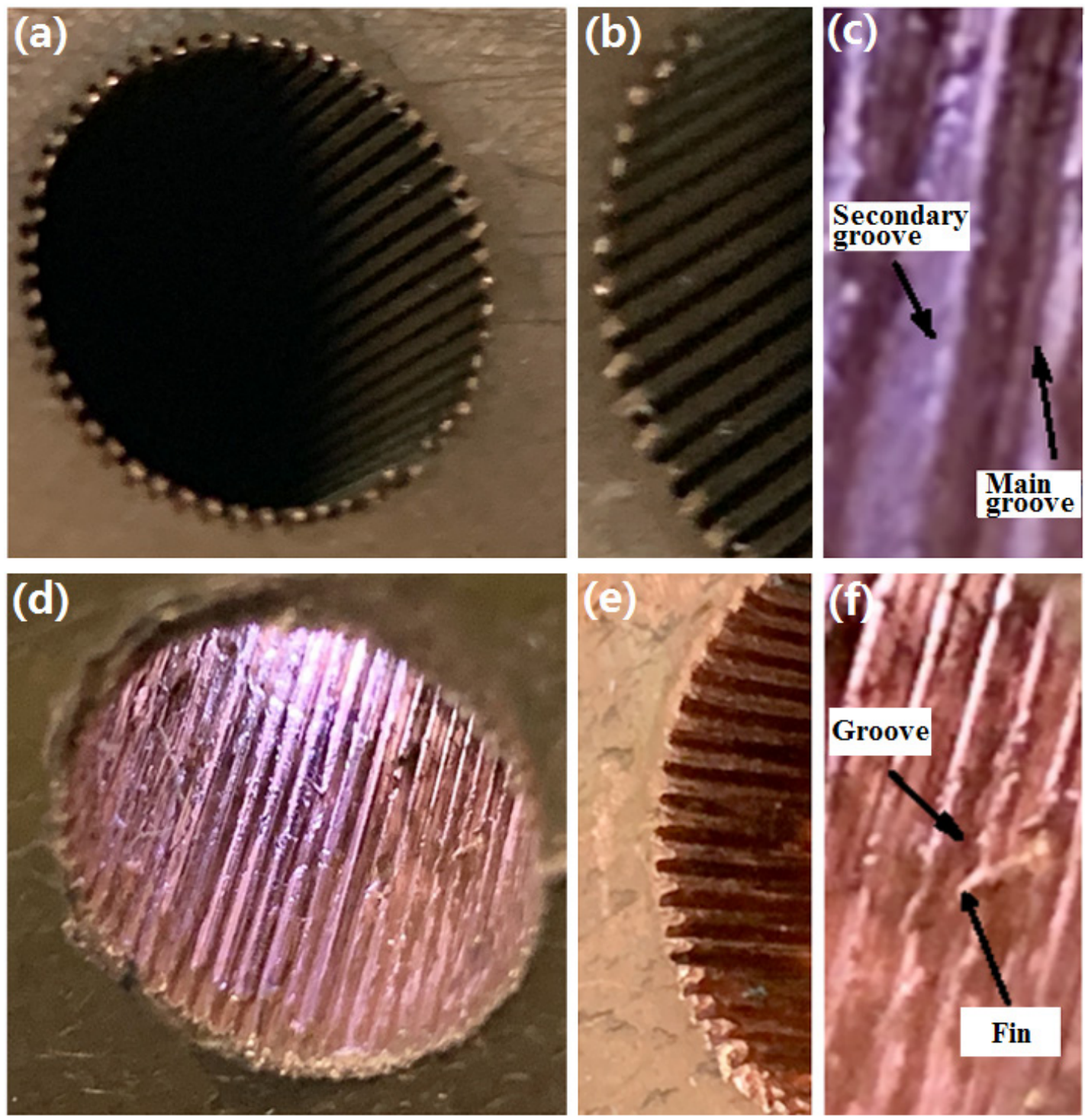

Fig. 9. The comparison between wire electrical discharge machining and plough-extrusion forming for making the structure of heat pipe; a) micro-grooves manufactured by wire electrical discharge machining, b) enlarged view of micro-grooves manufactured by wire electrical discharge machining, c) the structures of main and secondary grooves from enlarged view of micro-grooves manufactured by ploughextrusion forming, d) micro-grooves manufactured by plough-extrusion forming, e) enlarged view of micro-grooves manufactured by ploughextrusion forming, $f$ ) the structures of fin and groove from enlarged view of micro-grooves manufactured by plough-extrusion forming 
Table 1. Design parameters of multi-tooth tool

\begin{tabular}{|c|c|c|c|c|c|c|}
\hline Number of tool & 1 & 2 & 3 & 4 & 5 & 6 \\
\hline Tooth number & 50 & 50 & 55 & 55 & 60 & 60 \\
\hline Angle for each tooth $\left[^{\circ}\right]$ & 7.20 & 7.20 & 6.54 & 6.54 & 6.00 & 6.00 \\
\hline Tooth top width [mm] & 0.25 & 0.25 & 0.22 & 0.22 & 0.20 & 0.20 \\
\hline Tooth bottom width [mm] & $(0.1973)$ & $(0.1842)$ & $(0.1673)$ & $(0.1542)$ & $(0.1473)$ & $(0.1342)$ \\
\hline Tooth fin width [mm] & $(0.2527)$ & $(0.2527)$ & $(0.2365)$ & $(0.2365)$ & $(0.2189)$ & $(0.2189)$ \\
\hline Tooth depth [mm] & 0.2 & 0.25 & 0.2 & 0.25 & 0.2 & 0.25 \\
\hline
\end{tabular}

and then the photographed surface was compared and analysed. According to the comparison, it was found that the multi-tooth tool with $10 \mathrm{~mm}$ length, 55 tooth number, $0.25 \mathrm{~mm}$ tooth depth and $0.22 \mathrm{~mm}$ tooth top width, which corresponds to No. 4 in Table 1, could achieve the best performance in these six designed tools.

Different forming speed was also tested to determine the best setting. The testing ploughextrusion forming speed was increased from 30 $\mathrm{mm} / \mathrm{min}$ to $70 \mathrm{~mm} / \mathrm{min}$ using the tool with best performance, and the corresponding length, height, width and spacing of the formed fin structure were recorded in Fig. 10. It can be found that with the increase of plough-extrusion forming speed, the fin height, the fin width and the spacing between two fins changed little, and they tended to be stable.
Furthermore, the fin length varied slightly with speed. Thus, $50 \mathrm{~mm} / \mathrm{min}$ is taken to be the most suitable forming speed for acquiring the largest fin length in this experiment.

In order to verify the effectiveness of the theoretical model in guiding the actual manufacturing, the verification test was carried out in experiments. The heat pipes used for the verification were made of copper, and were formed by the multi-tooth tool with the parameters of No. 5 item in Table 1 according to the method described in this research. The number of the micro-grooves is 60 , the depth of the microgrooves is $0.20 \mathrm{~mm}$, and the bottom width of the micro-grooves is $0.15 \mathrm{~mm}$, the width of the top side of the micro-grooves is $0.20 \mathrm{~mm}$, and the micro-grooves are evenly distributed in the circumferential direction. The formed micro-groove copper tube shell was

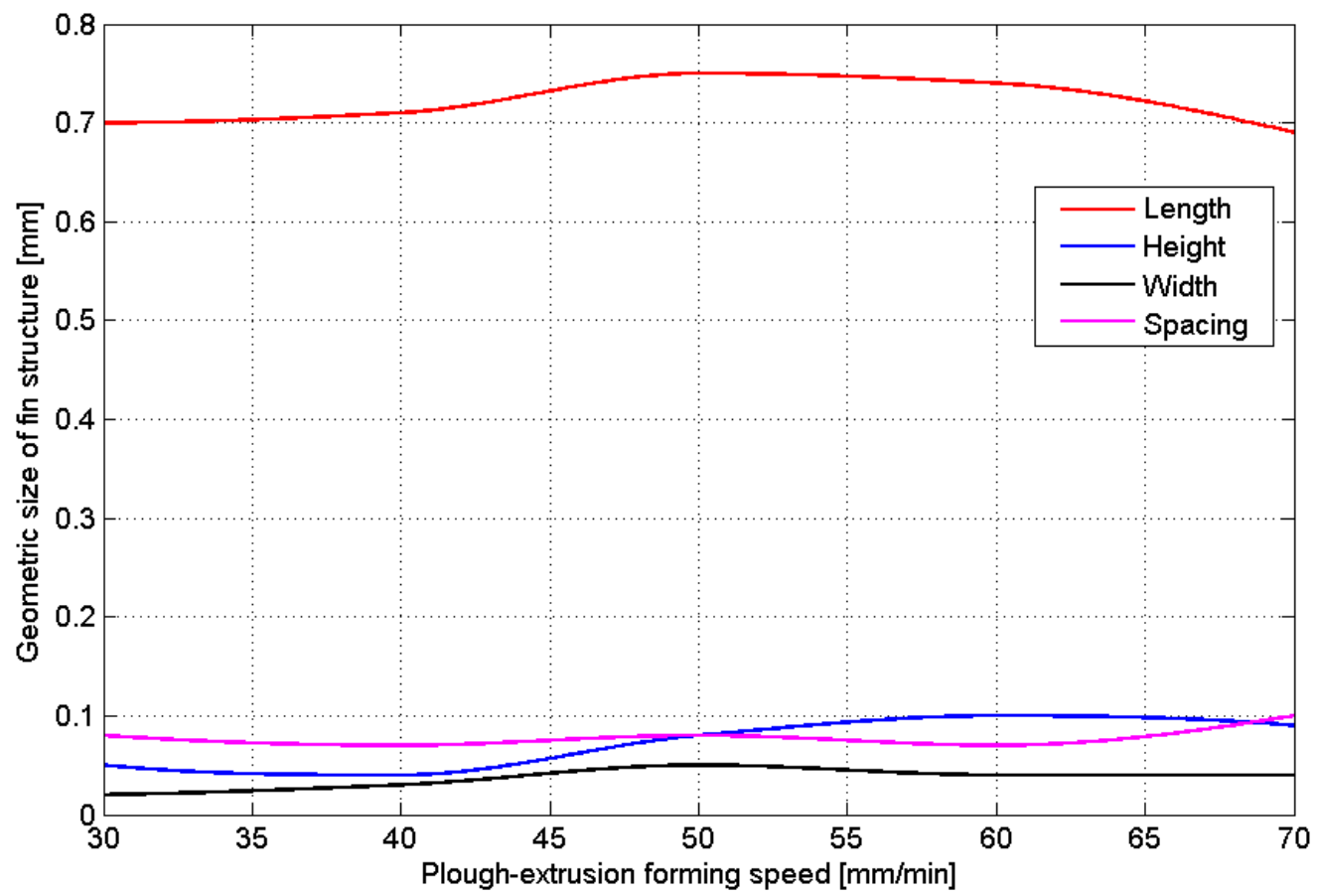

Fig. 10. The relationship between the plough-extrusion forming speed and the structure parameters of serrated fins 
pumped to a negative pressure of $1.3 \times\left(10^{-1}\right.$ to $\left.10^{-4}\right) \mathrm{Pa}$ and then filled with an appropriate amount of working fluid, which was water in the test, so that the capillary porous material of the wick was filled with liquid and then sealed to form a micro-groove heat pipe. During the test, the heat pipe is placed horizontally, the temperature of the evaporation section is kept at $60{ }^{\circ} \mathrm{C}$ and the condensation section is cooled with water to below $30^{\circ} \mathrm{C}$.

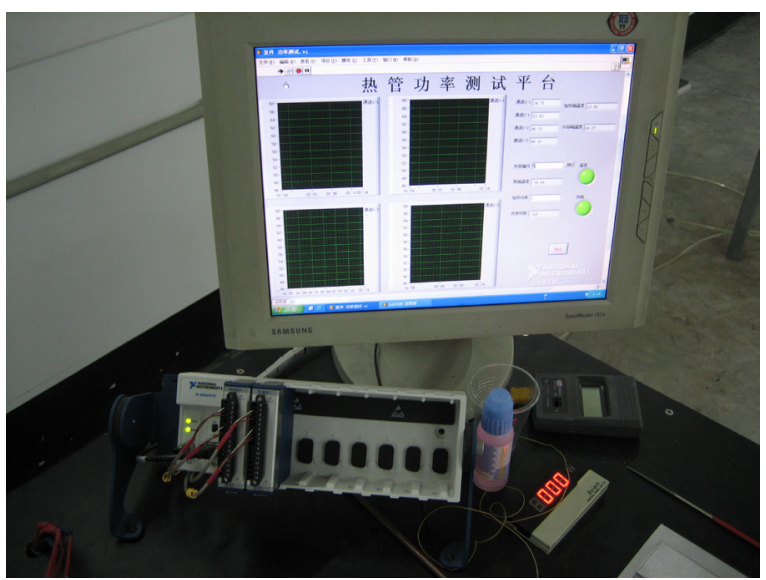

Fig. 11. Example of experimental system for heat transfer test

The effective length of the micro heat pipe is 235 $\mathrm{mm}$, of which the length of the evaporation section is $50 \mathrm{~mm}$, the length of the adiabatic section is $85 \mathrm{~mm}$, and the length of the condensation section is $100 \mathrm{~mm}$. The relevant parameters of water at $60{ }^{\circ} \mathrm{C}$ are shown as below: $M=18.0156, p_{v}=1.99919 \times 10^{4} \mathrm{~Pa}, h_{f g}$ $=2.3584 \times 10^{6} \mathrm{~kJ} / \mathrm{kg}, \rho_{l}=983.28 \mathrm{~kg} / \mathrm{m}^{3}, \rho_{v}=0.1302$ $\mathrm{kg} / \mathrm{m}^{3}, \mu_{l}=4.63 \times 10^{-4} \mathrm{~N} \cdot \mathrm{s} / \mathrm{m}^{2}, \mu_{v}=1.06 \times 10^{6} \mathrm{~N} \cdot \mathrm{s} / \mathrm{m}^{2}$, $k_{l}=0.653 \mathrm{~W} /(\mathrm{m} \cdot \mathrm{K}), \sigma=6.607 \times 10^{-2} \mathrm{~N} / \mathrm{m}$. According to the theoretical model described in Section 1, the theoretical parameters of the heat pipe can be calculated as below: its viscosity limit is $3.01 \times 10^{5}$ $\mathrm{W}$, sound velocity limit is $1.31 \times 10^{3} \mathrm{~W}$, carrying limit is $223 \mathrm{~W}$, capillary limit is $79.3 \mathrm{~W}$, and boiling limit is $6.82 \times 10^{3} \mathrm{~W}$. Because its maximum heat transfer is determined by the capillary limit, the maximum theoretical heat transfer of a micro-groove heat pipe with these parameters is $79.3 \mathrm{~W}$. Ten micro-groove heat pipes formed in the experiments with the same parameters as the theoretical sample were tested by the specific heat transfer testing system as shown in Fig. 11. Their heat transfers were $80.3 \mathrm{~W}, 78.6 \mathrm{~W}, 79.6$ W, 79.2 W, 78.9 W, 79.3 W, 79.7 W, 78.9 W, 80.1 W and $78.8 \mathrm{~W}$. The average value was $79.4 \mathrm{~W}$, which had a deviation of $0.1 \mathrm{~W}$ compared with the maximum theoretical heat transfer. Using the scanning electron microscope (SEM) to analyse the cross-section of the micro-groove heat pipe, it was found that due to the influence of various factors in the processing, as well as the influence of plastic deformation flow and partial recovery, there was a certain error in the actual micro-groove. However, the error between the experimental value and the theoretical value was within an acceptable range, and the model in Section 1 could be considered correct.

\section{CONCLUSION}

The heat transfer performance of the heat pipe mainly depends on the structure of the inner wall wick. The plough-extrusion forming method proposed in this paper can quickly make micro-grooves in the inner hole of flat. However, there are micro-chips in the machining process. In order to ensure smooth discharge of the chips, vertical top-down processing is adopted. According to image analysis of forming experimental results, the multi-tooth tool with $10 \mathrm{~mm}$ length, 55 tooth number, $0.25 \mathrm{~mm}$ tooth depth and $0.22 \mathrm{~mm}$ tooth top width was chosen to be the most suitable forming tool and the $50 \mathrm{~mm} / \mathrm{min}$ forming speed was taken to achieve optimization. During the manufacturing procedure, if the forming speed is too fast, the pull rod may be damaged. However, if the forming speed is too slow, the effect of ploughing is not obvious, and it is a waste of time.

\section{ACKNOWLEDGEMENTS}

This project is supported by the National Natural Science Foundation of China (grant no. 81701087), Natural Science Foundation of Fujian Province in China (2017J01681) and the Outstanding Youth Fund of Fujian Agriculture and Forestry University (XJQ201820).

\section{REFERENCES}

[1] Yu, M., Yu, X., Zheng, X., Jiang, H. (2019). Thermal-fluid-solid coupling deformation of hydrostatic thrust bearing friction pairs. Industrial Lubrication and Tribology, vol. 71, no. 3, p. 467-473, D0I:10.1108/ILT-07-2018-0262.

[2] Wang, D.Q., Yan, B.H., Chen, J.Y. (2020). The opportunities and challenges of micro heat piped cooled reactor system with high efficiency energy conversion units. Annals of Nuclear Energy, vol. 149, art. ID 107808, D0l:10.1016/j. anucene.2020.107808.

[3] Liang, L., Diao, Y.H., Zhao, Y.H., Wang, Z.Y., Bai, F.W. (2020). Numerical and experimental investigations of latent thermal energy storage device based on a flat micro-heat pipe arraymetal foam composite structure. Renewable Energy, vol. 161, p. 1195-1208, D0I:10.1016/j.renene.2020.07.033. 
[4] Mueller, C., Tsvetkov, P. (2020). Novel design integration for advanced nuclear heat-pipe systems. Annals of Nuclear Energy, vol. 141, art. ID 107324, D0l:10.1016/j. anucene.2020.107324.

[5] Gan, J.S., Yu, H., Tan, M.K., Soh, A.K., Wu, H.A., Hung, Y.M. (2020). Performance enhancement of graphene-coated micro heat pipes for light-emitting diode cooling. International Journal of Heat and Mass Transfer, vol. 154, art. ID 119687, DOI:10.1016/j.ijheatmasstransfer.2020.119687.

[6] Liu, Y., Jiang, T., Zheng, Y., Tian, J., Ma, Z. (2019). Multi-scale multi-field coupled analysis of power battery pack based on heat pipe cooling. Processes, vol. 7, no. 10, p. art. ID 696, DOl:10.3390/pr7100696.

[7] Chen, G., Tang, Y., Duan, L., Tang, H., Zhong, G., Wan, Z., Zhang, S., Fu, T. (2020). Thermal performance enhancement of micro-grooved aluminum flat plate heat pipes applied in solar collectors. Renewable Energy, vol. 146, p. 2234-2242, DOI:10.1016/j.renene.2019.08.083.

[8] Zeng, L., Liu, X., Zhang, Q., Yi, J., Li, X., Liu, X., Su, H. (2020). Experimental and simulation study of micro-channel backplane heat pipe air conditioning system in data center. Applied Sciences, vol. 10, no. 4, p. 1255, D0l:10.3390/ app10041255.

[9] Wang, G., Quan, Z., Zhao, Y., Wang, H. (2020). Effect of geometries on the heat transfer characteristics of flat-plate micro heat pipes. Applied Thermal Engineering, vol. 180, art. ID 115796, D0I:10.1016/j.applthermaleng.2020.115796.

[10] Hamidnia, M., Luo, Y., Li, Z., Wang, X. (2020). Capillary and thermal performance enhancement of rectangular grooved micro heat pipe with micro pillars. International Journal of Heat and Mass Transfer, vol. 153, art. ID 119581, D0I:10.1016/j. ijheatmasstransfer.2020.119581.

[11] Kiseev, V., Sazhin, 0. (2019). Heat transfer enhancement in a loop thermosyphon using nanoparticles/water nanofluid. International Journal of Heat and Mass Transfer, vol. 132, p. 557-564, D0I:10.1016/j.ijheatmasstransfer.2018.11.109.

[12] Chen, G., Tang, Y., Wan, Z., Zhong, G., Tang, H., Zeng, J. (2019). Heat transfer characteristic of an ultra-thin flat plate heat pipe with surface-functional wicks for cooling electronics. International Communications in Heat and Mass Transfer, vol. 100, p. 12-19, D0I:10.1016/j.icheatmasstransfer.2018.10.011.

[13] Yu, X., Fu, X., Meng, X., Liu, D., Zhang, Y., Wang, W. (2015). Experimental and numerical study on the temperature performance of high-speed circular hydrostatic thrust bearing. Journal of Computational and Theoretical Nanoscience, vol. 12, no. 8, p. 1540-1545, D0l:10.1166/jctn.2015.3925.

[14] Li, X., Li, W., Chen, X., Li, M., Chen, H., Yue, X. (2018). Design and performance analysis on heat pipe hydrostatic thrust bearings based on rectangular oil pad. Industrial Lubrication and Tribology, vol. 70, no. 7, p. 1251-1257, D0l:10.1108/ILT10-2017-0303.

[15] Li, X., Li, M., Li, M., Wu, R., Wan, Y., Cheng, T. (2016). Forming method of micro heat pipe with compound structure of sintered wick on grooved substrate. Heat and Mass Transfer, vol. 52, p. 581-593, D0l:10.1007/s00231-015-1585-4.
[16] Ramadhan, A.A., Anii, Y.T.A., Shareef, A.J. (2013). Groove geometry effects on turbulent heat transfer and fluid flow. Heat and Mass Transfer, vol. 49, p. 185-195, D0l:10.1007/ s00231-012-1076-9.

[17] Zhang, S., Lin, L., Chen, G., Tang, H., Zeng, J., Yuan, W., Tang, Y. (2019). Experimental study on the capillary performance of aluminum micro-grooved wicks with reentrant cavity array. International Journal of Heat and Mass Transfer, vol. 139, p. 917-927, D0I:10.1016/j.ijheatmasstransfer.2019.05.091.

[18] Wu, S., Dong, H., Huang, A., Lo, C., Chen, Y. (2018). Manufacturing and testing of the liquid grooves wick on the heat transfer performance in loop heat pipe with flat evaporator. DEStech Transactions on Environment, Energy and Earth Science, vol., p. 23777, D0l:10.12783/dteees/ epe2018/23777.

[19] Ömür, C., Uygur, A.B., Horuz, I., Işik, H.G., Ayan, S., Konar, M. (2018). Incorporation of manufacturing constraints into an algorithm for the determination of maximum heat transport capacity of extruded axially grooved heat pipes. International Journal of Thermal Sciences, vol. 123, p. 181-190, DOI:10.1016/j.ijthermalsci.2017.09.016.

[20] Nagayama, G., Gyotoku, S., Tsuruta, T. (2018). Thermal performance of flat micro heat pipe with converging microchannels. International Journal of Heat and Mass Transfer, vol. 122, p. 375-382, D0l:10.1016/j. ijheatmasstransfer.2018.01.131.

[21] Córcoles, J.I., Moya-Rico, J.D., Molina, A.E., AlmendrosIbáñez, J.A. (2020). Numerical and experimental study of the heat transfer process in a double pipe heat exchanger with inner corrugated tubes. International Journal of Thermal Sciences, vol. 158, art. ID 106526, D0I:10.1016/j. ijthermalsci.2020.106526.

[22] Chen, X., Sun, C., Xia, X., Liu, R., Wang, F. (2019). Conjugated heat transfer analysis of a foam filled double-pipe heat exchanger for high-temperature application. International Journal of Heat and Mass Transfer, vol. 134, p. 1003-1013, D0I:10.1016/j.jheatmasstransfer.2019.01.100.

[23] Busse, C.A. (1973). Theory of the ultimate heat transfer limit of cylindrical heat pipes. International Journal of Heat and Mass Transfer, vol. 16, no. 1, p. 169-186, D0l:10.1016/00179310(73)90260-3.

[24] Deverall, J.E., Kemme, J., Florschuetz, L. (1972). Sonic Limitations and Startup Problems of Heat Pipes. NASA Tech Brief.

[25] Faghri, A., Thomas, S. (1989). Performance characteristics of a concentric annular heat pipe: Part I-experimental prediction and analysis of the capillary limit. Journal of Heat Transfer, vol. 111 no. 4, p. 844-850, D0l:10.1115/1.3250795.

[26] Chi, S.W. (1976). Heat Pipe Theory and Practice. Hemisphere Publishing Corp., Washington, DC.

[27] Tien, C.L., Sun, K.H. (1971). Minimum meniscus radius of heat pipe wicking materials. International Journal of Heat and Mass Transfer, vol. 14, no. 11, p. 1853-1855, D0l:10.1016/00179310(71)90052-4.

[28] Kays, W.M. (2012). Convective Heat and Mass Transfer. Tata McGraw-Hill Education, New York. 